\title{
Reply
}

\section{Reply to the Letter to the Editor From Ivanov et al}

This is a very controversial field, not just for CHEK2 but many other genes. The more testing we do, the more variants are discovered and it is not always easy to determine which ones are actually associated with cancer incidence, which ones have a cancer risk that would change management or which ones are innocent bystanders. As a result, NCCN is continually reviewing the evidence and revising the guidelines as appropriate.

Mary B. Daly, MD, PhD

Chair, NCCN Guidelines

for Genetic/Familial High-Risk Assessment:
Breast, Ovarian, and Pancreatic Department of Clinical Genetics, Fox Chase Cancer Center Philadelphia, Pennsylvania

Email: Mary.Daly@fccc.edu doi: 10.6004/jnccn.2022.0014

\section{CALL FOR CORRESPONDENCE}

JNCCN is committed to providing a forum to enhance collaboration between academic medicine and the community physician. We welcome comments about the NCCN Guidelines, articles published in the journal, or any other topic relating to cancer prevention, detection, treatment, supportive care, or survivorship.

Please submit correspondence to www.editorialmanager.com/JNCCN.

Letters should be no more than 400 words, with no more than 5 references if included. NCCN reserves the right not to publish correspondence for any reason it deems appropriate. All letters are subject to editing and/or abridgment.

\section{NCCN Nursing Program: 2022 Advancing Oncology Nursing ${ }^{\text {TM }}$}

\section{NOW A VIRTUAL EVENT!}

NCCN.org/nursing-program 